\title{
A combined DNA-microsatellite and isozyme analysis of the population structure of the harbour porpoise in Danish waters and West Greenland
}

\author{
LISELOTTE WESLEY ANDERSEN* $\dagger$, LARS-ERIK HOLM $\ddagger$ HANS R. SIEGISMUND§, \\ BJARNE CLAUSEN $\dagger \dagger$, CARL C. KINZE $\$ \ddagger \&$ VOLKER LOESCHCKE $\dagger$ \\ †'nstitute of Biological Sciences, Department of Genetics and Ecology, University of Aarhus, DK-8000 Arhus, \\ $\ddagger$ Department of Breeding and Genetics, Danish Institute of Animal Science, Foulum, §Arboretum, Royal Veterinary \\ and Agricultural University, Kirkegårdsvej 3A, DK-2970 Hørsholm, ††Danish Environmental Research Institute, 4000 \\ Roskilde and $\$+Z o o l o g i c a l$ Museum, University of Copenhagen, Denmark
}

One hundred and twenty-four specimens of the harbour porpoise, Phocoena phocoena, occurring in inner Danish waters (IDW), the North Sea and West Greenland were analysed to study subdivision into genetically differentiated subpopulations using PCR-amplified DNA-microsatellites and isozyme markers. Three polymorphic microsatellites, 415/416, 417/418 and Igf-I (insulin-like growth factor I) were detected with nine, eight and 15 alleles, respectively, and from a former study two polymorphic isozymes, $\mathrm{Mpi}-1$ and $\mathrm{Pgm}$, with three and two alleles, respectively, were used in the analysis. Overall deviations from the expected Hardy-Weinberg distribution were only observed in the total sample and at a single locus in the North Sea-summer sample and at two loci in the West Greenland sample. Whenever this occurred a surplus of homozygotes was observed, suggesting a Wahlund effect, a null allele or nonrandom mating. The analysis of the genetical population structure showed that harbour porpoises from West Greenland, the North Sea and IDW were three geographically, genetically differentiated populations even though connected through some degree of gene flow. A tendency for females to be more stationary than males was suggested. Furthermore, the population structure suggested a closer relationship between IDW and the North Sea.

Keywords: Danish waters, harbour porpoise, microsatellite-DNA, population genetics, West Greenland.

\section{Introduction}

Three geographically isolated populations of the harbour porpoise, Phocoena phocoena, are found in the Northern Pacific, Black Sea, and North Atlantic, respectively (Gaskin, 1984). A growing concern about the health of the harbour porpoise populations in the North-east Atlantic is accentuated by the apparently high incidental mortality of porpoises and by the lack of knowledge about the impact this may cause on the populations (NMFS, 1992). In the evaluation of the potential impact it is of great importance to identify population structure. Studies

*Corresponding author. E-mail: lotte@pop.bio.aau.dk on the intraspecific variation of the harbour porpoise traditionally applied skeletal information such as skull measurements and nonmetric characters (Kinze, 1985; Yurick \& Gaskin, 1987). Gaskin (1984) suggested separate North Sea and Baltic subpopulations, whereas Kinze (1985) found significant differences between, on one side, Danish, North Sea and Baltic samples, and Dutch North Sea samples on the other side, and subsequently differences between inner Danish waters (IDW) and Skagerrak and North Sea individuals (Kinze, 1990).

The only analysis at present available on the genetical population structure of the Danish harbour porpoise is that of Andersen (1993), which was based on isozyme data. This study showed that the 
genotypic distribution of the total sample was influenced by locality and seasonal effects. The sample was then divided into two subpopulations, the IDW which was composed of individuals from Kattegat, the Belts and Baltic Sea, and the North Sea. The result of a genotypically based comparison between IDW and the North Sea showed significant differences which could indicate two genetically differentiated subpopulations.

As indicated in other studies of cetaceans like the pilot whale, Globicephala melas (Amos et al., 1991; Andersen \& Siegismund, 1994), and the sperm whale, Physeter macrocephalus (Whitehead, 1987), very often a sex-related migration takes place. In pilot whales males migrate between schools and in sperm whales big bulls move from one school to the next during the mating season. The question is whether a similar sex-related migration pattern can be found in the harbour porpoise. The present study concerns the subdivision into genetically differentiated subpopulations and the processes influencing this subdivision of the harbour porpoise occurring in IDW, the North Sea, and West Greenland based on information obtained from the combination of DNA-microsatellites and isozymes.

\section{Materials and methods}

Muscle tissue from 124 stranded and incidentally caught harbour porpoises was used from three supposed populations, West Greenland, IDW and the North Sea. All individuals in the West Greenland sample, the North Sea sample, and most of the individuals in the IDW sample were analysed in Andersen (1993). The 33 North Sea specimens were collected from August 1980 to January 1981 by Clausen \& Andersen (1988), and the 53 IDW specimens were collected from 1986 to 1991 by C. C. Kinze and H. H. Dietz (the latter of the National Veterinary Laboratory, Arhus, Denmark). The 38 specimens from West Greenland were collected at Manitsoq in 1989 by C. C. Kinze and represent only summer individuals.

Individuals collected primarily in the summer season from April to September which includes the breeding season were chosen for the analysis. This was a result of a hierarchical contingency table analysis of the effects of sampling period, locality and season on the genotypic distribution made by Andersen (1993). Mating takes place in July to August (Sørensen \& Kinze, 1994), which might also explain the seasonal effect and supports the selection of summer individuals to represent a subpopulation.

\section{DNA-extraction}

DNA was extracted from muscle tissue using $500 \mu \mathrm{L}$ grinding buffer $(150 \mathrm{~mm} \mathrm{NaCl}, 50 \mathrm{~mm}$ Tris $/ \mathrm{HCl}$, 2 mм EDTA, 0.5 per cent SDS pH $=8.0$ ), 10-20 $\mu \mathrm{L}$ Proteinase K $(10 \mathrm{mg} / \mathrm{mL})$ per sample and incubated overnight at $37^{\circ} \mathrm{C}$. The homogenate was extracted once with $500 \mu \mathrm{L}$ neutralized phenol $(\mathrm{pH}=8.0)$, once with $500 \mu \mathrm{L}$ neutralized phenol/chloroformisoamyl alcohol (24:24:1) and once with $500 \mu \mathrm{L}$ chloroform-isoamyl alcohol (24:1). $50 \mu \mathrm{L} 3.0 \mathrm{M}$ $\mathrm{NaAc}(\mathrm{pH}=5.2)$ and $50 \mu \mathrm{L} 5.0 \mathrm{M} \mathrm{NaCl}$ were added before DNA was precipitated with ethanol and dissolved in TE-buffer. DNA concentration was determined optically at $260 \mathrm{~nm}$.

\section{PCR-amplification of microsatellites}

Three microsatellite primer pairs were used. One is flanking the simple sequence locus $415 / 416$ and another is flanking locus $417 / 418$ described by Schlötterer et al. (1991) and Amos et al. (1993), respectively. The third is situated in the promoter region of the insulin-like growth factor I $(I g f-I)$ in pigs and cattle (Kirkpatrick, 1992). The three microsatellite primers had the following sequences:

\section{5/416 5'-GTTCCTTTCCTTACA 5'-ATCAATGTTTGTCAA \\ 417/418 5'-GTGATATCATACAGTA 5'-ATCTGTTTGTCACATA}

\section{Igf-1 5'-GGGTATTGCTAGCCAGCTGGT 5'-CATATTTTTCTGCATAACTTGAACCT}

The PCR reaction was carried out in $25 \mu \mathrm{L}$ volumes using $0.4 \mathrm{U}$ Taq polymerase, $0.15 \mathrm{~mm} \mathrm{MgCl}_{2}(2.5 \mu \mathrm{L}$ $10 \times$ buffer), $10-100 \mathrm{ng}$ DNA, $0.1 \mu \mathrm{M}$ primer, $100 \mu \mathrm{M}$ dNTP and water. The PCR conditions for locus $415 / 416$ and $417 / 418$ were 35 cycles of $1 \mathrm{~min}$ at $95^{\circ} \mathrm{C}$, $1 \mathrm{~min}$ at $40^{\circ} \mathrm{C}$ for locus $415 / 416$ and $46^{\circ} \mathrm{C}$ for locus $417 / 418$, respectively, and $2 \mathrm{~min}$ at $74^{\circ} \mathrm{C}$. PCR conditions for the Igf-I locus were 32 cycles of $1 \mathrm{~min}$ at $94^{\circ} \mathrm{C}, 45 \mathrm{~s}$ at $50^{\circ} \mathrm{C}$ and $10 \mathrm{~s}$ at $74^{\circ} \mathrm{C}$. One of the primers in each pair was fluorescently labelled at the 5 '-end for detection of the microsatellites. About 1 $\mu \mathrm{L}$ of the labelled PCR product was mixed with loading-buffer containing two markers of known sizes labelled with fluorescein and denatured at $94^{\circ} \mathrm{C}$ for $4 \mathrm{~min}$. The samples were then analysed on a 6 per cent denaturing polyacrylamide gel using the A.L.F. ${ }^{\text {TM }}$ DNA Sequencer (Pharmacia LKB, Pharmacia Biotech, Allerød, Denmark). For locus 415/416 a presumed null allele was observed, prob- 
ably caused by a mutation in one of the primer binding sites. It was not possible to establish this as no known mother-offspring pair was recognized. A solution to this problem was to run the PCR reaction three times before typing.

\section{Isozymes}

The method used was horizontal starch gel electrophoresis described in Andersen (1993) and the results from this former study are included in the present one. As a result of new statistical methods for analysing population genetical problems, the two polymorphic loci, $\mathrm{Mpi}-1$ and $\mathrm{Pgm}$, were reanalysed and the third observed rare allele at the Mpi-1 locus included.

\section{Statistical analysis}

As DNA-microsatellite loci are highly polymorphic, containing a high number of alleles, the problem of rare genotypes arises in the analysis of goodness of fit to the Hardy-Weinberg proportions and of possible geographical differentiation in the harbour porpoise. One way to overcome such a problem is a test for deviations from Hardy-Weinberg expectations by constructing a Markov chain using the genotype counts having the same allelic counts as the observed sample and an equilibrium distribution matching the genotype probabilities under HardyWeinberg proportions (Guo \& Thompson, 1992). In order to obtain an unbiased estimation of the fit to Hardy-Weinberg proportions the Markov chain should not be started from the observed data. This can be overcome by starting the chain from the observed data and allowing it to run for a long time so the initial state will be forgotten. This process is called 'dememorization' (Guo \& Thompson, 1992; Raymond \& Rousset, 1995a). The test was run for 1000 dememorizations, 300 batches, and 1000 iterations/batch. The $P$-value obtained is the sum of the probabilities with the same allele counts and which have the same or lower probability. According to Raymond \& Rousset (1995a) this is Haldane's (1954) and Guo \& Thompson's (1992) Hardy-Weinberg test. $F_{\text {IS }}$ is used to indicate the overall deviation from Hardy-Weinberg expectations, where $F_{\text {IS }}>0$ indicates a deficiency of heterozygotes. The test for Hardy-Weinberg proportions is performed with the computer-package GENEPOP developed by Raymond \& Rousset (1995a). The expected allele frequency of the presumed null allele at the 415/416 locus in the samples where it could be the cause of the significant observed deficit of heterozygotes, is estimated using $r=H_{\mathrm{e}}-H_{\mathrm{o}} / 1+H_{\mathrm{e}}$ (Brookfield, 1996). $r=$ estimated frequency of the null allele, $H_{\mathrm{e}}=$ expected frequency of heterozygotes, $H_{\mathrm{o}}=$ observed frequency of heterozygotes.

The possible geographical differentiation was analysed by testing if the allelic composition was independent of population assignment to generate the expected $\chi^{2}$ distribution if $\mathrm{H}_{0}$ was true for a given data set (Raymond \& Rousset, 1995b). This was also performed by using the GENEPOP program (Raymond \& Rousset, 1995a) which gives an unbiased estimate of the $P$-value obtained by Fisher's test on a $\mathrm{R} \times \mathrm{C}$ contingency table using a Markov chain method. Whenever a significant deviation from Hardy-Weinberg expectations was observed for one of the loci in the multilocus analysis of geographical differentiation, the genotype distribution of this particular locus was used in a contingency table analysis also based on a Markov chain method and run for 5000 dememorizations, 500 batches, and 5000 iterations/batch to obtain the test probability. The probabilities were then combined by Fisher's method (1970) for independent test results. Where multiple tests were run, the sequential Bonferroni procedure was applied (Rice, 1989) to give table-wide significance levels.

The geographical differentiation was also estimated from Wright's $F$-statistics (1951). The $F_{\mathrm{ST}}$ over the three microsatellite loci and two allozyme loci was estimated using Weir \& Cockerham's (1984) unbiased estimator, $\theta$.

Based on the variation of the five polymorphic loci, we used the 'assignment test' of Paetkau et al. (1995) to assign individuals collected during summer periods, and which had been genotyped at all five loci. The assignment is carried out by multiplying the expected genotype frequencies according to Hardy-Weinberg across all loci. An individual is assigned to the population that has the highest likelihood of containing a member with the observed multilocus genotype. The procedure assumes linkage equilibrium among all loci.

\section{Results}

Three microsatellite loci and two polymorphic allozyme loci were identified in the three supposed harbour porpoise populations/subpopulations. The $415 / 416$ locus and the $417 / 418$ locus consist of GT dinucleotide repeats and a total of nine and eight alleles were detected, respectively. The former ranges in size from 202 to 230 and the latter from 162 to 180 base pairs. The Igf-I locus also consists of GT dinucleotide repeats and a total of 15 alleles are 
detected ranging in size from 94 to 154 base pairs. Still no alleles from either of the loci have been sequenced so the study is based on the qualitative interpretations of the number of alleles from the obtained fluorograms. At the two polymorphic allozymes Mpi-1 and Pgm, three and two alleles were found as described by Andersen (1993).

In Table 1 tests for Hardy-Weinberg expectations (Guo \& Thompson, 1992) are shown for the harbour porpoise in Danish waters (North Sea and IDW) and West Greenland when they are divided into locality and season, and seasonal totals. After application of the sequential Bonferroni test on the seven overall probability tests a deficiency in heterozygotes was observed in the seasonal total. However, when considering single localities and a single locus, the $415 / 416$ showed significant differences from HWE in North Sea-summer and West Greenland. In the North Sea this significance was caused by the male sample, while the significance disappeared when the W.Greenland sample was divided into sex. When dividing the IDW-summer sample into sex a weak significant deviation $(P=0.044)$ from Hardy-Weinberg expectations was observed in the female sample at the $415 / 416$ locus. Significant deviation from Hardy-Weinberg proportions at the Igf-1 locus was observed in the West Greenland sample which was caused by the male sample. $F_{\text {Is }}$ was positive.

Table $1 P$-values for the goodness of fit of harbour porpoise populations to the Hardy - Weinberg expectations (Guo \& Thompson, 1992; Raymond \& Rousset, 1995a)

\begin{tabular}{|c|c|c|c|c|c|c|c|c|c|c|c|c|}
\hline & \multicolumn{2}{|c|}{$415 / 416$} & \multicolumn{2}{|c|}{$417 / 418$} & \multicolumn{2}{|c|}{$I g f-I$} & \multicolumn{2}{|c|}{ Mpi-1 } & \multicolumn{2}{|c|}{$P g m$} & \multirow{2}{*}{$\frac{\text { Combined }}{P}$} & \multirow[b]{2}{*}{$N$} \\
\hline & $F_{\text {IS }}$ & $P$ & $F_{\text {IS }}$ & $P$ & $F_{\text {IS }}$ & $P$ & $F_{\text {IS }}$ & $P$ & $F_{\text {IS }}$ & $P$ & & \\
\hline IDW-summer-males & -0.051 & 0.883 & 0.149 & 0.582 & 0.027 & 0.171 & 0.039 & 0.717 & -0.160 & 1.000 & 0.114 & 32 \\
\hline IDW-summer & 0.111 & 0.164 & 0.154 & 0.525 & 0.069 & 0.298 & -0.024 & 0.730 & -0.028 & 1.000 & 0.633 & 53 \\
\hline North Sea-summer-males & 0.436 & 0.004 & 0.025 & 0.235 & 0.174 & 0.113 & -0.272 & 0.211 & 0.016 & 1.000 & 0.018 & 17 \\
\hline North Sea-summer & 0.352 & 0.015 & -0.031 & 0.443 & 0.063 & 0.251 & -0.216 & 0.201 & 0.127 & 0.496 & 0.067 & 33 \\
\hline W. Greenland-males & 0.311 & 0.148 & 0.074 & 0.437 & -0.005 & 0.018 & -0.048 & 1.000 & 0.355 & 0.262 & 0.095 & 17 \\
\hline W. Greenland & 0.286 & 0.022 & 0.029 & 0.168 & 0.027 & 0.029 & -0.065 & 0.815 & 0.210 & 0.122 & 0.020 & 38 \\
\hline $\begin{array}{l}\text { W. Greenland + North Sea } \\
\text { + IDW-summer }\end{array}$ & 0.240 & 0.0004 & 0.058 & 0.250 & 0.078 & 0.072 & -0.067 & 0.567 & 0.157 & 0.094 & $0.001^{*}$ & 124 \\
\hline
\end{tabular}

$F_{\mathrm{IS}}$, inbreeding coefficient indicating deviation from Hardy-Weinberg proportions. $P$ combined $=$ combined probability over all loci in the given sample or combination of samples (Fisher, 1970), d.f. $=10 . N$, sample size.

Table 2 Tests for allele frequency differences among North Sea, inner Danish waters and West Greenland harbour porpoise populations (Raymond \& Rousset, 1995a).

\begin{tabular}{|c|c|c|c|c|c|c|}
\hline & NSSUFE & W.GRFE & NSSUMA & W.GRMA & NSSU & W.GR \\
\hline IDWSUFE & $\begin{array}{l}14.09 \\
(0.169)\end{array}$ & $\begin{array}{l}18.91 \\
(0.041)\end{array}$ & & & & \\
\hline NSSUFE & $\begin{array}{l}18.98 \\
(0.041)\end{array}$ & $\begin{array}{l}12.37 \\
(0.261)\end{array}$ & & & & \\
\hline IDWSUMA & & & $\begin{array}{l}29.02 \\
(0.001 *)\end{array}$ & $\begin{array}{l}18.44 \\
(0.048)\end{array}$ & & \\
\hline NSSUMA & & & $\begin{array}{l}28.04 \\
(0.002 *)\end{array}$ & $\begin{array}{l}14.47 \\
(0.153)\end{array}$ & & \\
\hline IDWSU & & & & & $\begin{array}{l}39.66 \\
\left(0.00002^{*}\right)\end{array}$ & $\begin{array}{l}26.77 \\
\left(0.003^{*}\right)\end{array}$ \\
\hline NSSU & & & & & $\begin{array}{l}46.74 \\
(0.000 *)\end{array}$ & $\begin{array}{l}31.65 \\
\left(0.00046^{*}\right)\end{array}$ \\
\hline
\end{tabular}

$P$ (in brackets) $=$ combined test probabilities for all loci $($ d.f. $=10)$. IDW, inner Danish waters; SU, summer; FE, females; MA, males; W.GR, West Greenland; NS, North Sea. 
Table 2 presents allele frequency differences among the three assumed populations of harbour porpoises based on contingency table tests (Raymond \& Rousset, 1995b). Highly significant deviations in allele frequencies were observed after application of the sequential Bonferroni test (Rice, 1989 ) in the pairwise multilocus comparisons between IDW-summer-males-North Sea-summermales, between IDW-summer-North Sea-summer, between IDW-summer-West Greenland and between North Sea-summer-West Greenland, and when all three populations were combined in the multilocus comparisons IDW-summer-males-North Sea-males-West Greenland-males and IDW-summer-North Sea-summer-West Greenland.

Geographical differentiation of the three populations and the different subsamples conditioned on season was also estimated in terms of Wright's $F$-statistics using Weir and Cockerham's estimator, $\theta$. The mean $F_{\mathrm{ST}}$ jackknife-value over all loci for IDW-summer-North Sea-summer-West Greenland was $F_{\mathrm{ST}}=0.031 \pm 0.013$. When evaluating the standard deviation of the $F_{\mathrm{ST}}$-estimate in a $t$-test, $F_{\mathrm{ST}}$ was significant $(P<0.05)$.

The result of the 'assignment test' of Paetkau et al. (1995) is presented in Table 3 for individuals collected during summer periods. A total of 65 individuals (55 per cent) were assigned to the sampling area where they had been collected. For the IDW and North Sea areas, the largest fraction of individuals placed in another population was assigned to either the North Sea or the IDW, respectively, and a smaller fraction to the West Greenland area.

\section{Discussion}

The $415 / 416$ and $417 / 418$ microsatellite loci that Amos et al. (1993) found to be polymorphic with six and three alleles, respectively, in the long-finned pilot whale, Globicephala melas, were also present in the harbour porpoise, Phocoena phocoena, but much

Table 3 Multilocus assignment of individuals from summer periods to the three harbour porpoise populations, IDW, North Sea and West Greenland

\begin{tabular}{lcccc}
\hline & \multicolumn{4}{c}{ Percentage assignment to } \\
\cline { 2 - 5 } Sampling area & IDW & NS & W.GR & $N$ \\
\hline IDW-summer & 0.47 & 0.29 & 0.24 & 51 \\
NS-summer & 0.22 & 0.63 & 0.16 & 32 \\
W.GR & 0.20 & 0.20 & 0.60 & 35 \\
\hline$N$
\end{tabular}

$N$ is the sample size. more variable, as nine and eight alleles, respectively, were detected in this species. The Igf-I locus was also highly variable, with 15 alleles in total in the three supposed populations.

The tests for concordance with Hardy-Weinberg expectations showed no overall significant deviations after application of the sequential Bonferroni test (Table 1). Nevertheless, when testing for significantly different allele frequencies in the pairwise multilocus analysis and in the multilocus analysis of the combination of the three populations some of the localities did show significant deviations from Hardy-Weinberg expectations. Most frequently deviations were observed at locus $415 / 416$ and locus Igf-I mainly in the different combinations of the North Sea sample. They all displayed a surplus of homozygotes which could indicate a Wahlund effect or nonrandom mating, but for locus $415 / 416$ a segregating null allele also could be responsible for this pattern. The expected allele frequency of the null allele in the North Sea-summer-males, North Sea-summer, West Greenland and in the total sample was $0.179,0.137,0.033$ and 0.088 , respectively. Meanwhile, this method of estimating the expected allele frequency of the null allele assumes that all heterozygote deficiencies in relation to Hardy-Weinberg expectations can be explained by a null allele and not by a subdivision of the population. This assumption is not met by any of the samples in question. Instead, observations of heterozygote deficiency in the North Sea sample do support the results from the isozyme study of the population structure of the Danish harbour porpoise (Andersen, 1993). Here, the significant deviation from Hardy-Weinberg proportions was explained by a mixing of several subpopulations in the North Sea or nonrandom mating. The suggestion of mixing of several subpopulations was supported by the nature of the sampling of individuals in the North Sea, which represented a wide geographical area and therefore probably several breeding areas (Clausen \& Andersen, 1988). The deviation from HardyWeinberg proportions found in the West Greenland sample in the present study could also be explained by a mixing of several subpopulations or by inbreeding. The samples from West Greenland were collected from individuals taken in a direct hunt which is conducted by the Innuits for subsistence. These individuals are most likely hunted in different areas, but more information about the exact area does not exist. More individuals should be analysed to answer the question about the population structure off West Greenland. The significant deviation from the Hardy-Weinberg proportions in the total 
sample is expected as this consists of the pooling of several populations, so the assumption concerning the estimation of the expected null allele frequency is again violated, and the most probable explanation for the deficiency of heterozygotes at the 415/416 locus is a mixing of several populations or nonrandom mating. The observed homogeneity in the IDW sample suggests that there is no detectable population structure in this sample, which could imply that the IDW sample is a relict of a Baltic Sea subpopulation.

To analyse the genetical population structure, tests for allele frequency differences between the three assumed harbour porpoise populations/subpopulations were conducted in a multilocus pairwise and three-way comparison (Table 2). In Andersen (1993) a seasonal effect was shown to influence the genotypic distribution at the Pgm locus, which corresponded well with the observation of a formerly described seasonal migration of harbour porpoises out of the Baltic into the North Sea in winter (Møhl-Hansen, 1954). As a result of these observations and of the fact that harbour porpoises in Danish waters mate during July and August (Sørensen \& Kinze, 1994), the geographical differentiation was tested among the summer samples, which is the best approach to get a true picture of the populations. A highly significant difference between the three summer samples was detected, which again strongly suggests the existence of three genetically different populations. A pairwise comparison between IDW, North Sea and West Greenland based on season and sex showed that the summer sample of the North Sea was geographically differentiated from the West Greenland sample and IDW-summer sample, and that IDW-summer was geographically differentiated from West Greenland. This differentiation is caused by the summer-male samples in the IDW and North Sea $(P<0.01)$ which probably can be explained by more than one population in the North Sea. This is expected, but it was not possible to detect this differentiation in the allozyme study. The population structure was also analysed in terms of $F_{\mathrm{ST}}$ using the methods of Weir \& Cockerham (1984). The significant $F_{\mathrm{ST}}$-value observed for IDW-summer-North Sea-summerWest Greenland underlines and supports the results of allele frequency differences, so we can conclude, on the basis of the present samples representing the three populations, that they are three genetically distinct populations, but with some degree of gene flow between them. In a study of the genetical population structure of the North Pacific harbour porpoise based on sequencing of the control region in mtDNA, Rosel et al. (1995) also detected a significant $F_{\mathrm{ST}}$-value when stratifying the samples into individuals collected off California, Washington, British Columbia and Alaska, indicating the existence of at least four putative populations in this area.

The result of the 'assignment test' (Table 3) also points to a genetic differentiation of the three sampling areas, and it furthermore suggests a closer relationship between the IDW-summer and North Sea-summer samples compared to IDW-summerWest Greenland and North Sea-summer-West Greenland. In the present study 65 individuals out of 118 were assigned to the sampling area where they were collected which is very close to the result Paetkau et al. (1995) obtained in their study of the population structure of the Canadian polar bear. They correctly assigned 65 out of 108 individuals to their respective populations, which were based on genotypes from eight microsatellite markers. This procedure by simply estimating an individual's genotype characteristics for the populations in question seems to be another good approach to use as an estimate for population differentiation (Paetkau et al., 1995).

The analysis of the genetic population structure of the harbour porpoise in Danish waters and West Greenland based on three microsatellite loci and two allozyme loci gives a consistent picture that allows us to conclude that these three populations are geographically differentiated into three genetically distinct populations, with a closer relationship between the IDW-summer and North Sea-summer populations, and connected through a fairly high amount of gene flow. Females tend to return to the same breeding area every year, whereas males tend to stray more, returning to different breeding areas, at least in the North Sea. Males in IDW seem to return to the breeding areas in the IDW, which implies that the IDW sample represents a relict of a Baltic Sea population. The analysis of the West Greenland sample also suggested the existence of more than one population. To elucidate further these population structure indications more samples from different areas in the North Sea and from West Greenland should be analysed using DNAmicrosatellites.

\section{Acknowledgements}

We thank all the people involved in collecting material from the harbour porpoises for this study. A special thanks to the staff in the laboratory at the Danish Institute of Animal Science, Department of 
Breeding and Genetics, Foulum, Denmark for their help during the study. Thanks also to P. Hedrick for valuable comments and discussion of the manuscript, to $M$. M. Hansen and $M$. Niclasson for constructive discussions and to R. Krebs for reviewing and editing the English. This study was funded by the Danish Natural Science Research Council, Jr.Nr. 11-0642-1 and The Danish National Forest and Nature Agency.

\section{References}

AMOS, W., BARRETT, J. AND DOVER, G. 1991. Breeding behaviour of pilot whales revealed by DNA fingerprinting. Heredity, 67, 49-55.

AMOS, B., SCHLÖTTERER, C. AND TAUTZ, D. 1993. Social structure of pilot whales revealed by analytical DNA-profiling. Science, 260, 670-672.

ANDERSEN, L. W. 1993. The population structure of the harbour porpoise, Phocoena phocoena, in Danish waters and part of the North Atlantic. Mar. Biol., 116, 1-7.

ANDERSEN, L. W. AND SiEGISMund, H. R. 1994. Genetic evidence for migration of males between schools of the long-finned pilot whale, Globicephala melas. Mar. Ecol. Progr. Ser., 105, 1-7.

BROOKF1ELD, J. F. Y. 1996. A simple new method for estimating null allele frequency from heterozygote deficiency. Mol. Ecol., 5, 453-455.

ClAUSEN, B. AND ANDERSEN, S. H. 1988. Evaluation of bycatch and health status of the harbour porpoise (Phocoena phocoena(L.)) in Danish waters. Dan. Rev. Game Biol., 13, 1-20.

FISHER, R. A. 1970. Statistical Methods for Research Workers, 14th edn. Oliver and Boyd, Edinburgh.

GASKIN, D. E. 1984. The harbour porpoise, Phocoena phocoena (L.). Regional populations, status and information on direct and indirect catches. Rep. Int. Whaling Comm., 34, 569-586.

Guo, s. W. AND THOMpson, E. A. 1992. Performing the exact test for Hardy-Weinberg proportion for multiple alleles. Biometrics, 48, 361-372.

HALDANE, J. B. S. 1954. An exact test for randomness of mating. J. Genet., 52, 631-635.

KINZE, C. C. 1985. Intraspecific variation in Baltic and North Sea harbour porpoises (Phocoena phocoena (L., 1978). Vidensk. Meddr. Dansk Naturh. Foren., 146, 63-74.

KINZE, c. c. 1990. The harbour porpoise (Phocoena phocoena (L.): Stock identification and migration patterns in Danish and adjacent waters. PhD Thesis, Zoological Museum, University of Copenhagen.

KIRKPATRICK, B. w. 1992. Identification of a conserved microsatellite site in porcine and bovine insulin-like growth factor-I gene $5^{\prime}$ flank. Anim. Genet., 23, 543-548.

MØHL-HANSEN, B. U. 1954. Investigations on reproduction and growth of the harbour porpoise, Phocoena phocoena (L.), from the Baltic. Vidensk. Meddr. Dansk Naturh. Foren., 116, 369-396.

NMFS, NATIONAL MARINE FISHERIES SERVICE. 1992. Harbour porpoise in eastern North Atlantic: status and research needs. Northeast Fisheries Science Center Reference Document 92-06. NOAA/NMFS/NEFSC, Woods Hole, USA.

PAETKAU, D., CAlverT, w., STIRLING, 1. AND STROBeck, C. 1995. Microsatellite analysis of population structure in Canadian polar bears. Mol. Ecol., 4, 347-354.

RAYMOND, M. AND ROUSSET, F. 1995a. GENEPOP (V. 1.2). A population genetics software for exact tests and ecumenicism. J. Hered., 86, 248-249.

RAYMOND, M. AND ROUSSET, F. 1995b. An exact test for population differentiation. Evolution, 95, 1280-1283.

RICE, W. R. 1989. Analyzing tables of statistical tests. Evolution, 43, 223-225.

ROSEL, P. E., DIZON, A. E. AND HAYGOOD, M. G. 1995. Variability of the mitochondrial control region in populations of the harbour porpoise, Phocoena phocoena, on interoceanic and regional scales. Can. J. Fish. Aquat. Sci., 52, 1210-1219.

SCHLÖTTERER, C., AMOS,w. AND TAUTZ, D. 1991. Conservation of polymorphic simple sequence loci in cetacean species. Nature, 354, 5463-5467.

SøRENSEN, T. B. AND KINZE, C. C. 1994. Reproduction and reproductive seasonality in Danish harbour porpoises, Phocoena phocoena. Ophelia, 39, 159-176.

WEIR, B. S. AND COCKERHAM, c. c. 1984 . Estimating $F$-statistics for the analysis of population structure. Evolution, 38, 1358-1370.

WHITEHEAD, H. 1987. Social organization of sperm whales off Galápagos: implications for management and conservation. Rep. Int. Whaling Comm., 37, 195-199.

WRIGHT, s. 1951. The genetical structure of populations. Ann. Eugen., 15, 323-354.

YURICK, D. B. AND GASKIN, D. E. 1987. Morphometric and meristic comparison of skulls of harbour porpoise, Phocoena phocoena (L.), from the North Atlantic and North Pacific. Ophelia, 27, 53-75. 